\title{
Environmental protection by a framework code for risk analysis
}

\author{
R. Ippolito ${ }^{1} \&$ C. Salierno ${ }^{2}$ \\ ${ }^{I}$ Department of Nuclear Engineering and Energy Conversions, \\ University of Rome "La Sapienza", Italy \\ ${ }^{2}$ APAT (Italian Environmental Protection Agency, \\ Department of Nuclear, Technological and Industrial Risk, Italy
}

\begin{abstract}
All treatment and management activities of radioactive wastes and modalities of limitation of their release into the environment are regulated in Italy by Decree 230/95 and its integrative modifications. Environmental questions are really difficult to solve because of the complicated relationships among many contributing factors, both natural and man-made. Each nuclear installation must manage and check its own environmental surveillance network, thanks to which it is possible to examine the main critical pathways of the radioactivity in the environment and food chains. APAT verifies, approves and acquires all reference data from this environmental network for use in anomalous situations, to confirm or eventually to modify previewed results by mathematical models, that have been employed for the evaluation of the concentrations in the environmental matrices and doses to the critical groups, as a consequence of radioactive releases. The purpose of this work is to characterize, through dynamic models, typical scenes about areas interested in industrial and nuclear power plants. It has been possible to estimate the release and transport of the chemical elements throughout the environment, and to predict associated exposure and risk, using a framework software developed by Pacific Northwest National Laboratory for EPA (U.S. Environmental Protection Agency). The characterization of the area on which the structure insists, built up environment, population and vocation of the territory, contributes to the punctual analysis and allows one to estimate and to prevent the risk from sources of ionizing radiations.
\end{abstract}

Keywords: environmental protection, population protection, risk analysis, assessment and management. 


\section{Italian environmental surveillance program}

Each industrial or nuclear installation (as defined by Decree 230/95 art. 7) discharges into the environment some kind of emissions, deriving from processing products of the system itself.

All radioactive releases from nuclear systems into the environment are preventively authorized from the Ministry of the Economic Development in the within of the License of Exercise; the authorization of the "formula of discharge" is function of the real necessities of the system, in relation of its environmental receptivity, understanding as degree of acceptability of the receiving system, considering all pathways of return to the man through the food chain. The effects deriving from the radioactive emissions into the environment are continually controlled, thanks to an environmental surveillance program whose requirements are managed from the specific regulation list in matter of protection from the ionizing radiations: law 1860/1962, legislative decrees 230/1995 (Art 54 and 104 describe the duty and the responsibilities both of the license keepers and of regional or national environmental agencies, ARPA and APAT), 241/2000 and $257 / 2001$.

The most important goal of an environmental surveillance program is that one to estimate both real or potential risk for population, due to the presence of radioactive substances in the environment in which it mainly lives, in terms of total dose, understanding as sum of effective dose deriving from external exposure, and effective dose deriving from inhalation and ingestion of food matrices. Each radionuclide, introduced into the environment, both in liquid shape or in airborne one, follows numerous and complex ways through which it can cause undue exposure to man.

Each evaluation does not consider all pathways and all present radionuclides, for the reason that there are more important exposures ways and radionuclides, respect to others, to determine the risk. Consequently, the "critical radionuclides" are defined and associated to one critical exposure pathway and to critical matrix (e.g. iodine 131 in the pasture grass and successive milk ingestion from part of children, selected as critical age group).

In the same way a critical group of the population, whose both social and behavioural characteristics are such to render them mainly sensitive to the presence of radionuclides in the atmosphere in which they live, is characterized.

\subsection{Environmental surveillance networks}

The surveillance networks are articulated in complex way around to the system, dependent on the factors as: typologies of the system, main radionuclides and their chemical-physical shape, ways of release, climatic and geo-hydrology site characteristics, behavior of the population, the use of the local products and main ways of exposure.

The main exposure ways, about airborne dispersions, are: external exposure, deriving from immersion in the cloud or from the ground on which radionuclides are deposited; direct or resuspension inhalation; ingestion of directly contaminate products or re-entering in the food chain. 
As regards the waters contamination, these factors must be considered: external radiation, vapor inhalation, direct and indirect ingestion of products. In the end, to estimate ground contamination, it is important to consider: external exposure, inhalation for powder resuspension, and ingestion of contaminated matrices.

The environmental surveillance network will have to preview: measures of external and internal exposure, assessment of the atmospheric particulate concentrations, concentrations of the radionuclides both in the food and environmental matrices. The location and amount of the sampling points will be based on several factors as release nature, site geo-hydrology, meteorological conditions, critical groups distribution around the nuclear plant.

\subsection{Duty of the license keeper and tasks of the control authority}

All duties dictated from the art. 54 (Italian Decree 230/95) are entrusted to the owner of the license which predisposes an adapted environmental surveillance program; instrumentation and qualified staff, assures applications of assessment methodologies and measure opportunely validated, audits periodically the program in relation to the system characteristics, to the boundary situation and to normative references.

APAT, as specified in DPR 207/2002, has the task to approve of the environmental monitoring program, proposed by the license keeper, introducing, if it is necessary, the proposals and/or the prescription, and to supervise on the correct performance of the same program. The vigilance is explained through the verification of annual reports brought back in the environmental surveillance rapport, transmitted by the license keeper to APAT, the verification of the techniques and instrumentation applied, the vigilance on the measure and sampling modalities, the introduction, when opportune, of added controls with the aid of measures of laboratory or through the use of dedicated calculation codes.

\section{Methodologies}

The environmental and radiological impact assessment has been made using the software FRAMES (Framework for risk analysis in multimedia environmental system), developed by the Pacific Northwest National Laboratories, valid both for chronic releases and for acute ones.

In reality the software used like forecast model, is not a calculation code but a framework software that supports and connects different typologies and models of simulations; thanks to all this, it is possible to make an environmental impact assessment and calculate the dose to the population due to the contaminant dispersion both chemical and radioactive.

FRAMES is the graphical interface of the calculation code GENII 2,0 whose approach is of stochastic type and implements the methodology of calculation "Sensitivity Uncertainty Multimedia Modeling Module" and also incorporate the 
internal dosimetry models $26,30,48,56$, and 72 , with factors of dose from radiation of the Federal Guidance Report 12 and 13, recommended by the International Commission on Radiological Protection.

These dosimetry and risk models are considered to be 'state of the art' by the international radiation protection community and have been adopted by most national and international organizations as their standard dosimetry methodology. It is important to underline that the considered factor of dose are more conservative than what Italian laws describes; sometimes It is appropriate to change and fit the dose values in order to respect what each country regulations say (Decree 230/95).

The simulator considers four independent atmospheric models, one surface water model, three independent environmental accumulation models, one exposure module, and one dose/risk module, each with a specific user interface code. The software estimates the impact on the different critical groups of the population, both for programmed and impulsive releases. The direct exposure ways are the water, the ground, the air, the inhalation and the ingestion; moreover for the tritium is always considered an absorption model through the skin. The software encloses various calculation algorithms regarding airborne and liquids releases, that explain models of spread, transport, deposition, depletion and decay of the radionuclides in the biosphere. For the airborne releases, the framework code uses the Gaussian solution of the diffusion equation, that previews two assessment models for which it is possible to choose between continuous or impulsive releases, that are: the Gaussian plume model and the Lagrangian-puff model.

\section{Experimental study}

In the latest part of the this document we report a realistic study about liquid and airborne effluents discharge in a plant in wich there are different typologies of nuclear installations such as researche reactors, subcritical storage, post irradiations studies' laboratories, nuclear accelerators, solid and liquid waste treatment and conditioning plants.

In this specific case, the software FRAMES-GENII 2.0, analyses environmental impact coming from discharge of autorizated "discharge formula", for chronic releases for liquid and airborne effluents.

In order to obtain a real rapresentation of simulation, it's necessary to model the scenario utilizing specific parameters for the site and for the releases too.

The Figure 1 represents specific situation for airborne effluent releases; there are different glyphs that describe the real situation:

- Constituent: this module allows the user to select concerning constituents

- User defined: this module is used when the airborne emission rates in air are known and to describe boundary conditions;

- Air module Chronic plume: it provides to estimate ambient air concentration, dry and wet deposition rates and cloud shine dose. The atmospheric and surface depositions are computed using standard Gaussian dispersion models. The model can use either hourly meteorological data or wind and stability measurements. 
- Exposure Pathways: It may be used to estimate concentrations in exposure media for groundwater, surface water and atmospheric transport pathways. The results are written in annual increments for the duration of exposure defined by the user. Exposure pathways include domestic water use, agricultural product consumption, aquatic food consumption, recreational surface water activities and soil contamination pathways.

- Receptor intake: this module may be used to estimate annual intakes from exposure to contaminated soil, groundwater, surface water and atmospheric transport pathways in 6 different critical age groups. In this module we introduce local and specific informations about domestic water use, farm product consumption, surface water recreational activities, soil contact exposure and air exposures.

- Health impact: it calculates health impacts from intake or exposure to radionuclides. This impact may be reported as radiation dose or cancer incidence.

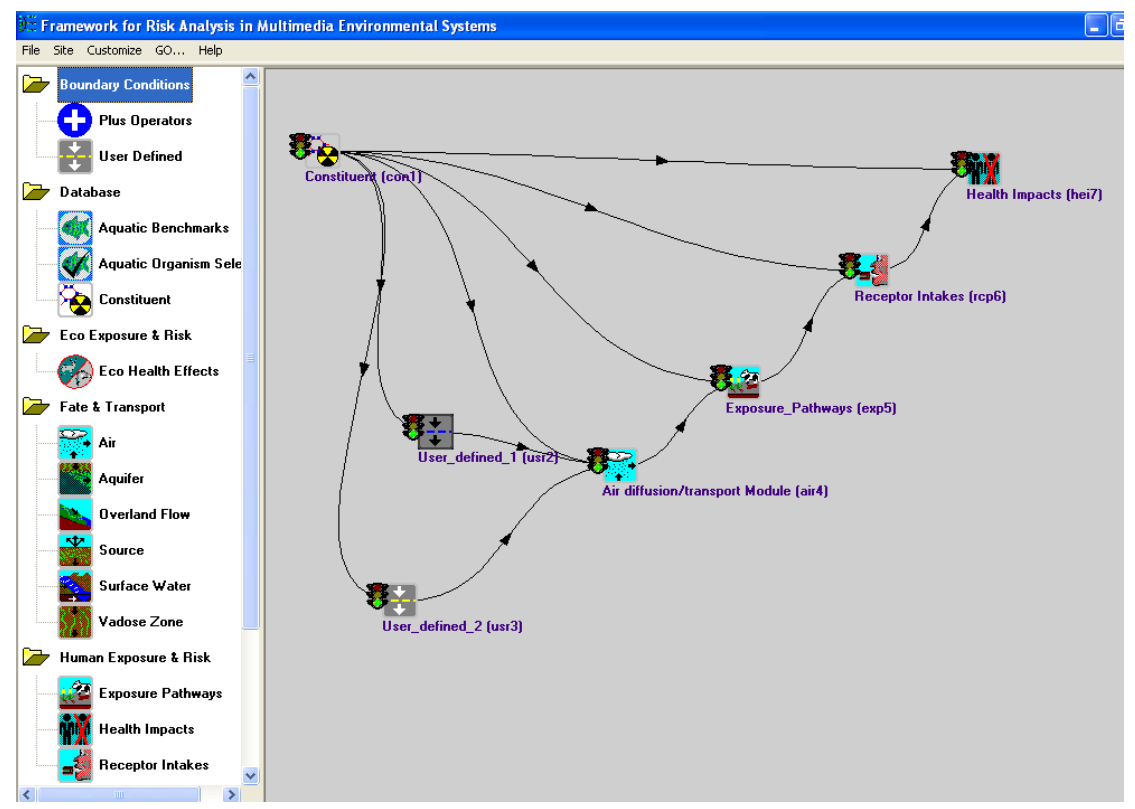

Figure 1: Airborne releases: scenario lay-out.

Concerning liquid releases, the real situation has been simulated by the mask represented in Figure 2; in this case we have a particular situation where liquid is released first in a torrent and after in a lake. The main glyphs in this simulation are: Constituent, User defined, Surface water, Exposure pathways, Receptor intakes and Health impact.

The glyph " user defined" is directly connected with real discharge conditions; in fact, the user has to choice the model of liquid transport in this part of code and depending on knowledge of flux rates, adsorbed flux and dissolved flux. 


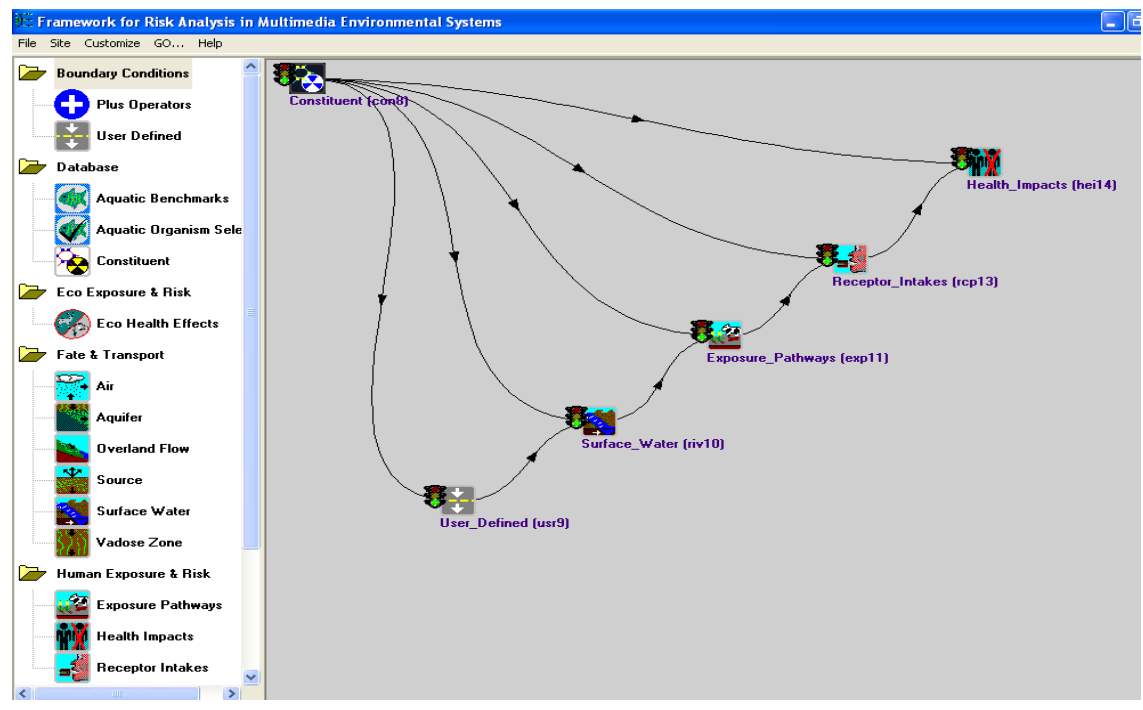

Figure 2: Liquid releases: scenario lay-out.

The GENII V.2 surface water module may be used to estimate radionuclide water concentration downstream from a release point. Some models are included to describe acute or chronic releases to rivers or lake environments.

\subsection{Tools}

The Department of Environmental Science (DEA) of University of Naples has developed supporting tools in order to use better FRAMES.

They refer, in particular, to programs such as Change-Settings and Reader.

\subsubsection{Change settings}

The first difficulty to use FRAMES is that numerical data are set in English format that use the "full stop" as decimal separator. In order to use this code on Italian PC, this software is used to change quickly the format from American to Italian.

\subsubsection{Reader}

A particular limit of FRAMES is the difficulty to analyze and to interpret the output data. In order to make this part of study easy, DSA has created a program called Reader; this program allows one to represent data, using clear graphics and simple tables. This program may be selected in a "stand-alone" form or in "embedded" form. The next figures show graphical examples of data output of Reader, concerning airborne (Figs. 3, 4) and liquid releases (Figs. 5, 6).

\subsection{Comparison between experimental data and theoretical data}

The following paragraph explains the comparison between experimental data obtained from environmental samples measurement and then described in annual relation, and theoretical data obtained by FRAMES-GENII simulation. 


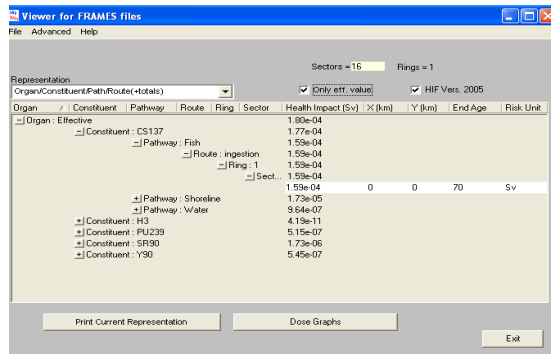

Figure 3: Airborne releases data output.

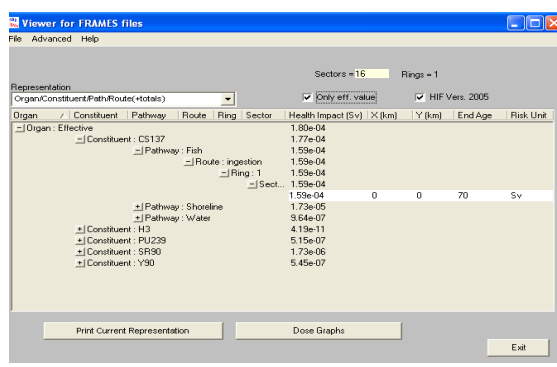

Figure 5: Liquid releases data output.

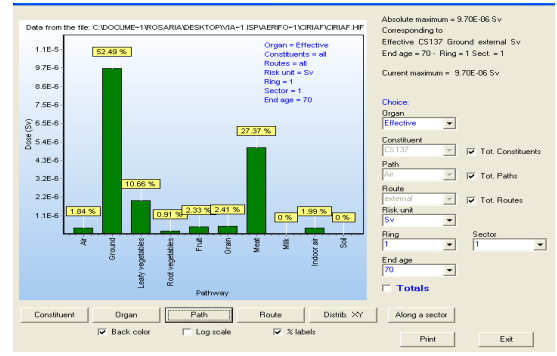

Figure 4: Data output graphical view.

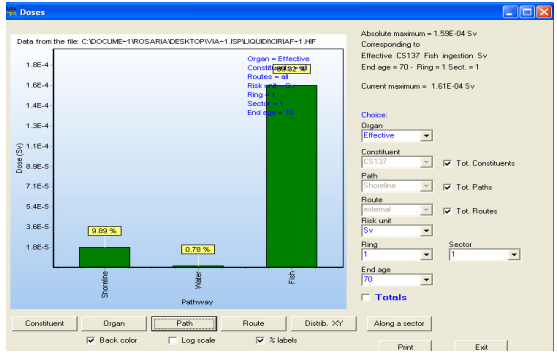

Figure 6: Data output graphical view.

\subsection{Simulation by FRAMES_GENII}

Hypothesis for code calculation are the follows:

For airborne discharge:

1. $100 \%$ of discharge formula with $\mathrm{HTO}$ (tritium steam) and $\mathrm{Cs} 137$;

- $\quad \mathrm{HTO}(\mathrm{Bq} /$ year $)=7.40 \mathrm{E}+13$

- $\quad$ Cs137(Bq/year $)=7.40 \mathrm{E}+10$

2. worst scenario for discharge (height of release lower than height of real chimney and release through only one point);

3. only adults, that live around the site between 1000 and $1500 \mathrm{~m}$ from point of release, are considered as critical group;

4. worst modeling for local datasets.

\subsubsection{Dose estimations for airborne effluents}

Maximum doses per EXPOSURE PATHWAYS,

Max individual dose: $\mathbf{5 7} \mu \mathrm{Sv} /$ year (Fig. 7)

Maximum doses per NUCLIDE,

Max individual dose: $57 \mu$ Sv/year (Fig. 8) 


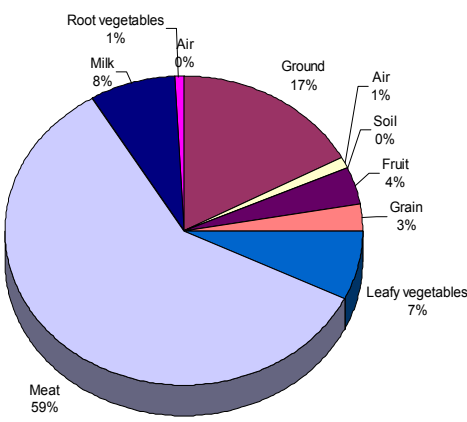

Figure 7: Max individual dose per Figure 8: EXPOSURE PATHWAYS.

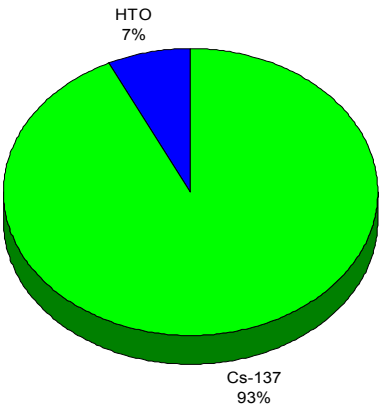

Max individual dose per NUCLIDE.

\subsubsection{Dose estimations for waterborne effluents}

For liquid discharge hypothesis are:

1. $100 \%$ of discharge formula in term of H3, Cs $137, \mathrm{Sr} 90$ and Pu239

2. worst scenario for discharge (doubtful + active effluents)

3. critical group consisting of adults that live around the site;

4. worst modeling for local datasets.

Table 1.

\begin{tabular}{|c|c|}
\hline Radionuclides & $\begin{array}{c}\text { doubtful + active (Bq/year) } \\
\text { Discharge (A) }\end{array}$ \\
\hline H-3 & $2.42 \mathrm{E}+07$ \\
\hline Sr-90 & $1.25 \mathrm{E}+08$ \\
\hline Cs-137 & $8.50 \mathrm{E}+08$ \\
\hline Pu-239 & $7.10 \mathrm{E}+06$ \\
\hline
\end{tabular}

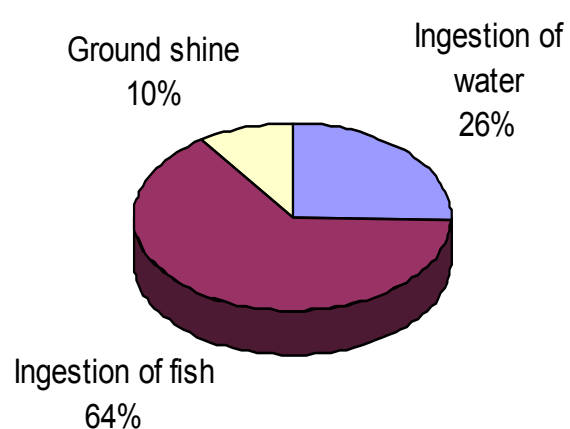

Figure 9: Max individual dose per Figure 10: EXPOSURE PATHWAYS.

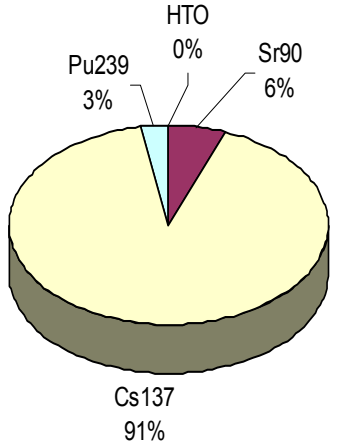

Max individual dose per NUCLIDE. 
Dose per EXPOSURE PATHWAYS, Individual Dose $173 \mu \mathrm{Sv} / \mathrm{year}$ - adults (Fig. 9)

Dose per NUCLIDE, Individual Dose $173 \mu$ Sv/year - adults (Fig. 10)

\subsection{Experimental measurements}

The surveillance environmental network is composed of several direct and indirect points of measurement and of samples taken inside and outside the site. In particular, measurement on samples allows one to calculate critical radionuclides concentration and consequently effective dose to critical group. All controls are made as follows:

\section{Air and deposition}

There are several fixed filters to collect, daily, weekly and monthly, atmospheric particulate; in addiction, there are a lot of TLD environmental dosimeters

Water and sediments

Water contamination is controlled through samples' measurements on surface water, groundwater and sediments.

Food chain

Matrices controlled are soil, milk, forage, fish, leafy vegetable and honey. Airborne and liquid radioactive effluents

Radioactive effluents released on chimney are monitored continuously; liquid effluents are controlled before every discharge.

Gamma dose in the air

TLD dosimeters are installed in meaningful points and are periodically read.

In Table 2 are reproduced liquid and airborne effluents discharged during 2005.

Table 2.

\begin{tabular}{|c|c|c|c|c|c|c|c|c|c|c|c|c|}
\hline EFFLUENTI & \begin{tabular}{|c|} 
Guartit: \\
cosrlosta \\
$m^{3}$
\end{tabular} & $\begin{array}{l}\text { Alfa totalo } \\
M B q\end{array}$ & $\begin{array}{c}\text { Boka totaio } \\
M B Q\end{array}$ & $\begin{array}{l}\text { Trlalo } \\
M B q\end{array}$ & $\begin{array}{l}\mathrm{CG}-187 \\
M B q\end{array}$ & $\begin{array}{l}C 0-80 \\
M B q\end{array}$ & $\begin{array}{l}\text { Am.241 } \\
M 6 q\end{array}$ & $\begin{array}{l}8 \mathrm{8r}-80 \\
M B Q\end{array}$ & $\begin{array}{l}R \rightarrow-228 \\
M B q\end{array} \mid$ & $\begin{array}{l}\text { Fa-228 } \\
M B q\end{array} \mid$ & \begin{tabular}{|c|} 
Atrin qamma \\
MEq
\end{tabular} & $\begin{array}{c}\text { \% dal Ilimite dl } \\
\text { 8carico annuo } \\
\text { autorizzato }\end{array}$ \\
\hline aerlforml & $1,64 \mathrm{E}+09$ & NA. & N.A. & $1,97 E+05$ & 0,00 & 0,00 & 0,00 & 0,00 & 0,00 & 0,00 & 0,00 & 0,27 \\
\hline |lquid| & 40,00 & 0,42 & 7,53 & 70,35 & 7,82 & 0,53 & 0,48 & 3,63 & 0,00 & 0,15 & 0,16 & 0,29 \\
\hline
\end{tabular}

\section{Conclusions and results}

Analyzing all results, it can be concluded that those deriving from code output and those experimentally measured are in satisfactory conformity, considering the wide conservatism consequent to following calculation hypotheses:

- the radiological inventory considered corresponds to $100 \%$ of the authorized "formula of discharge", while in reality only small fractions are used;

- the most critical scenarios, which assume a total and therefore not realistic consumption of the native products, have been simulated; 
- any important hypotheses have not been considered such as the effective prohibition to utilize the river water to irrigate and the prohibition to fish on all the river basin, also considering the effective product scarcity.

In Table 3 are compared the real measurements in terms of measured and foreseen concentration, as reported in Annual Report, and the results of the code FRAMES-GENII.

Table 3 .

\begin{tabular}{|c|c|c|c|c|}
\hline Matrix & $\begin{array}{l}\text { Preview } \\
\text { Concentration }\end{array}$ & $\begin{array}{l}\text { Measured } \\
\text { Concentration }\end{array}$ & $\begin{array}{l}\text { Concentr } \\
\text { FRAMES }\end{array}$ & Comments \\
\hline $\begin{array}{l}\text { atmospheric } \\
\text { Particulate } \\
\left(\mathrm{Bq} / \mathrm{m}^{3}\right)\end{array}$ & Cs137 & Cs137: $2,1 \times 10^{-6}$ & $4 \mathrm{E}-3$ & $\begin{array}{l}\text { Cs137 not discharged in } \\
\text { atmosphere, Chernobyl and } \\
\text { nuclear tests effects }\end{array}$ \\
\hline $\begin{array}{|ll|}\begin{array}{l}\text { Water } \\
\left(\mathrm{Bq} / \mathrm{m}^{3}\right)\end{array} & \text { Vapor } \\
\end{array}$ & HTO: $9,1 \times 10^{-4}$ & HTO: $1,5 \times 10^{-2}$ & 3.98 & \\
\hline $\begin{array}{ll}\text { River } & \text { water } \\
(\mathrm{Bq} / \mathrm{L}) & \end{array}$ & $\begin{array}{l}\text { HTO: } 1,6 \times 10^{-2} \\
\text { Cs137: } 1,7 \times 10^{-3} \\
\text { Am241: } 8,8 \times 10-5\end{array}$ & $\begin{array}{l}\text { HTO: } 4,9 \times 10^{-1} \\
\text { Cs137: } 3,3 \times 10^{-2} \\
\text { Am241: } 2,5 \times 10^{-2}\end{array}$ & $\begin{array}{l}0.005545 \\
0.1948 \\
0.001627\end{array}$ & $\begin{array}{l}\text { MAR per HTO. } \\
\text { Other radionuclides: } \\
\text { combined effect of Chernobyl, } \\
\text { discontinuous releases and } \\
\text { accumulation effects. }\end{array}$ \\
\hline $\begin{array}{l}\text { Sediments } \\
(\mathrm{Bq} / \mathrm{kg})\end{array}$ & $\begin{array}{l}\text { Co60: } 4,8 \times 10^{-1} \\
\text { Cs137: } 1,7 \times 10\end{array}$ & $\begin{array}{l}\text { Co60: } 2,6 \times 10^{-1} \\
\text { Cs137: } 1,8 \times 10\end{array}$ & 2.6 & $\begin{array}{l}\text { MAR per Co60. } \\
\text { Other radionuclides: } \\
\text { combined effects of } \\
\begin{array}{ll}\text { Chernobyl, discontinuous } \\
\text { releases and } \\
\text { effects }\end{array} \\
\end{array}$ \\
\hline Fish $(\mathrm{Bq} / \mathrm{kg})$ & \begin{tabular}{l|} 
HTO: $1,6 \times 10^{-2}$ \\
Co60: $3,6 \times 10^{-2}$ \\
Sr90: $5,0 \times 10^{-2}$ \\
Cs137: $3,6 \times 10$ \\
Am241: $3,3 \times 10^{-3}$ \\
\end{tabular} & \begin{tabular}{|lr} 
Not & available \\
sample &
\end{tabular} & $\begin{array}{l}0.005545 \\
1.719 \\
389,7 \\
0.004882 \\
\end{array}$ & \\
\hline Milk $(\mathrm{Bq} / \mathrm{L})$ & Cs137: 0 & & 3.15 & $\begin{array}{l}\text { Cs137 not discharged in } \\
\text { atmosphere, Chernobyl and }\end{array}$ \\
\hline Forage $(\mathrm{Bq} / \mathrm{kg})$ & Cs137: 0 & & 26.9 & accumulation effects \\
\hline
\end{tabular}

\section{References}

[1] Italian Decree $n^{\circ} 230$ on March 1995

[2] Rollo C. - Principi di sorveglianza ambientale- APAT 2002

[3] IAEA Safety Report Series $n^{\circ}$ 19: Generic Models of Use in Assessing the Impact of Discharges of Radioactive Substances to the Environment

[4] GENII-FRAMES, Environmental Radiation Dosimetry Software System EPA 2004

[5] ICRP 37-Principle of environmental monitoring related the handling of radioactive materials.

[6] ICRP 72-Age Dependent Doses to Members of Public from intake of Radionuclides 